\title{
Models of Mantle Viscosity
}

\author{
Scott D. King
}

\section{INTRODUCTION}

The viscosity of the mantle is one of the most important, and least understood material properties of the Earth. Plate velocities, deep-carthquake source mechanisms, the stress distribution in subduction zones, and estimates of geochemical mixing time scales are all strongly affected by the pattern of convective flow which, in turn, is strongly influenced by the viscosity structure of the mantle. There are two approaches to understanding the viscosity structure of the Earth: using observations such as the geoid and post-glacial uplift, combined with flow models; or studying the physical deformation properties of mantle minerals in the laboratory. Both approaches have advantages and drawbacks.

Laboratory measurements of deformation indicate that the rheology of upper mantle minerals such as olivine $\left((\mathrm{Mg}, \mathrm{Fe})_{2} \mathrm{SiO}_{4}\right)$ is a strong function of temperature, grain size and stress [e.g., 3, 24, 43, 45, 46, 61, 65]. The deformation of minerals under mantle conditions generally follows a flow law of the form

$$
\dot{\varepsilon}=A\left(\frac{\sigma}{\mu}\right)^{n} d^{-m} \exp \left(-\frac{Q}{R T}\right)
$$

where $\dot{\varepsilon}$ is the deformation rate, $\sigma$ is the deviatoric stress, $\mu$ is the shear modulus, $d$ is the grain size of the rock, $Q$ is the activation energy for the deformation mechanism, $T$ is the temperature in Kelvins, $R$ is the gas constant and $A$ is a

S. D. King, Purdue University, Department of Earth and Atmospheric Sciences, West Lafayette, IN 47907-1397

Mineral Physics and Crystallography

A Handbook of Physical Constants

AGU Reference Shelf 2

Copyright 1995 by the American Geophysical Union. constant [c.f., 3, 43]. Viscosity is defined as

$\eta=\frac{\sigma}{2 \dot{\varepsilon}}$

therefore, deformation is directly related to viscosity. (Note the factor of 2 difference in equation (2) compared with the definition used by experimentalists.) For temperature changes of 100 degrees $K$, the viscosity changes by an order of magnitude at constant stress [c.f., 44]. Changes of deviatoric stress by a factor of 2 change the viscosity by an order of magnitude [c.f., 44]. Other factors, such as partial pressure of oxygen and water may also have important effects.

Two creep mechanisms are likely to dominate in the mantle; diffusional flow (corresponding to $n=1$ in equation 1) and power-law creep (corresponding to $n>1$ in equation 1). A rheology with a linear stress strain-rate creep mechanism, such as diffusional flow, is referred to as a Newtonian rheology. The question of which mechanism dominates in the mantle depends on the average grain size of the mantle minerals [46]. In the upper mantle, with grain sizes greater than $1 \mathrm{~mm}$, power-law creep should dominate at stresses greater than $1 \mathrm{MPa}$; otherwise diffusion creep dominates [46]. A deformation map (Figure 1) shows the predicted dominant deformation mechanisms for olivine with grain size $0.1 \mathrm{~mm}$ as a function of stress and depth. It should be noted that the strain rates achieved in the lab (typically $10^{-5}-10^{-8} \mathrm{~s}^{-1}$ ) are much larger than those predicted in the lithosphere and mantle $\left(\sim 10^{-14} \mathrm{~s}^{-1}\right)$. While the laboratory measurements are clearly in the power-law creep field, typical mantle strain-rates lie close to the diffusional flow field at this small grain size.

The deformation of the major high pressure mantle phases perovskite $\left((\mathrm{Mg}, \mathrm{Fe}) \mathrm{SiO}_{3}\right)$ and spinel 


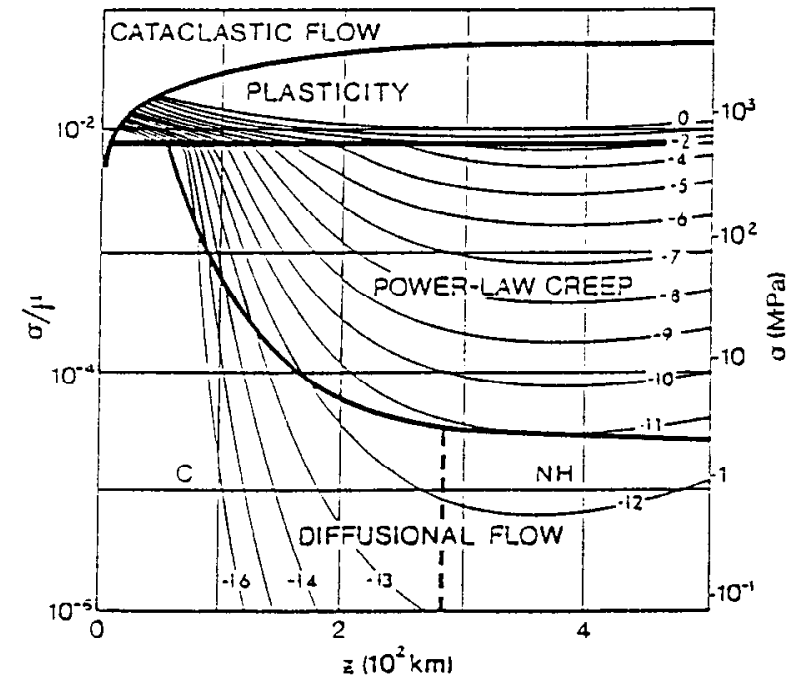

Fig. 1. $(\sigma-z)$-deformation map for polycrystalline olivine with grain size $0.1 \mathrm{~mm}$. Thick lines are creep field boundaries; thin lines, constant strain rate contours (given as powers of 10). $\mathrm{C}$ and $\mathrm{NH}$ denote Coble and NabarroHerring creep, respectively [3].

$\left((\mathrm{Mg}, \mathrm{Fe})_{2} \mathrm{SiO}_{4}\right)$ can be studied only by analog minerals. Using high temperature creep experiments on a $\mathrm{CaTiO}_{3}$ perovskite analog, Karato and $\mathrm{Li}$ [22] suggest the possibility of a weak zone at the top of the lower mantle (due to the grain size reduction from the spinel to perovskite phase change). Karato [21] showed that olivine, spinel and perovskite have similar normalized flow stresses, which suggests that, due to the effect of pressure, the lower mantle should have a higher viscosity than the upper mantle. Since creep parameters can differ greatly even for apparently-similar perovskites [44; Table 5], we should apply analog creep measurements to the mantle with great care.

Because of the difficulties in interpreting and applying laboratory creep measurements to mantle conditions, models of mantle viscosity based on large-scale geophysical observations continue to be important to geophysics. The post-glacial uplift problem, as described by Haskell [19], is a simple illustration. If a load is placed on the surface of a viscous fluid and allowed to deform the surface to establish hydrostatic equilibrium, the rate at which the surface deforms will depend on the viscosity of the fluid. Similarly, if the load is then removed, the rate of return is also dependent on viscosity. Viscosity models deduced from these observations are not unique, however, and requirc knowledgc of models for the surface load (i.e., ice sheet thickness and history), which are uncertain. Also, the theoretical models arc often simplificd to kecp them tractable; commonly, a linear rheology (i.e. $n=1$ and $T$ constant in equation (1)), which varies only with depth, is assumed.

The classic studies of post-glacial rebound illustrate the non-uniqueness of viscosity models derived from observations and flow models. Haskell $[19,20]$ proposed that the uplift of Fennoscandia was the result of deep flow, modeled as a half space with a uniform viscosity of $10^{21}$ $\mathrm{Pa} s$ (pascal seconds are the MKS units of dynamic viscosity; $1 \mathrm{~Pa} \mathrm{~S}=10$ poise), while van Bemmelem and Berlage [64 - see 5] proposed that the uplift of central Fennoscandia could be attributed to flow in a $100 \mathrm{~km}$ thick channel, with $1.3 \times 10^{19} \mathrm{~Pa}$ s viscosity, overlying an effectively rigid mantle. Haskell also showed that the viscosity did not change over the interval of time of the analysis, supporting the notation of a Newtonian, rather than stress-dependent mantle.

The effects of an elastic lithosphere were first discussed by Daly [7], who appealed to the strength of the lithosphere to avoid the formation of a bulge of material squeezed out of the low viscosity channel peripheral to the ice load in his model. McConnell [28] and Cathles $[4,5]$ showed the strength of the elastic lithosphere as important only in considering the short wavelength harmonics. O'Connell [33] determined the viscosity of the lower mantle by looking at changes in the ice load and relating them to long wavelength rebound. He also used spherical harmonic correlation to look for the rebound signal in the geoid. The effect of phase changes in the mantle on rebound was considered by O'Connell [34]. O'Connell concluded that the effect of both the olivine-spinel and the basalt-eclogite phase change on post-glacial are rebound negligible. Peltier [37] solved for the response of a viscoelastic (Maxwell) spherical Earth using the correspondence principle, later adding the effects of varying sea level [42]. The correspondence principle asserts that one can construct the Laplace transform of the solution by solving a series of elastic problems over a range of complex frequencies and then inverting to get the time domain response for the viscoelastic problem. Cathles $[4,5]$ presented an alternative viscoelastic formulation which avoids the complexities of the boundary conditions for long time periods when using the correspondence principle. Cathles argues for an increase in viscosity in the lower mantle, while Peltier argues for a uniform viscosity mantle. Because no direct comparison of the two methods has been reported, it is difficult to assess whether the differences between Peltier's and Cathles' conclusions are due to their methods or ice models. An ice sheet disintegration model, including ice masses of Laurentia, Fennoscandia, and Greenland, called 
ICE-1, was developed by Peltier and Andrews [40]. A summary of ice sheet models is provided by Peltier [39].

Lambeck and co-workers have used far field absolute sea level changes, rather than the rebound histories at sites near formerly-glaciated regions $[26,32]$. They reason that relative sea level variations far from ice margins are less influenced by poorly-constrained ice models. The difference between Nakada and Lambeck's models based on relative sea level variations in the Pacific, and models based on Fennoscandian and Canadian Uplift could be interpreted as reflecting lateral variations in upper mantle viscosity.

Table 1 compares a number of recently published viscosity models from post-glacial rebound with geoid and plate velocity studies compiled by Hager [14]. Because of the limited power in the post-glacial rcbound data set, rebound models are usually reported in very simple parameterizations. The models still range from the nearlyuniform viscosity (Haskallian) model PT to strongly layered models NL and HRPA (see Table 1).

Another constraint on mantle viscosity comes from modeling the geoid and dynamic topography of the surface and core mantle boundary, using the pattern of density anomalies inferred from seismic tomography $[11,16,17$, $18,23,49,50,51]$. From early seismic tomography, it has been observed that long-wavelength (i.e., spherical harmonic degree $1=2,3$ ) geoid lows are associated with long-wavelength, fast (presumably denser) regions in the lower mantle [9]. In a static Earth, this is opposite of what one predicts; geoid highs should correspond to mass excesses (Figure 2a). As shown by Pekris [36] (and others since), a mass anomaly will drive flow that deforms the surface and core mantle boundary (Figure $2 b$ or $2 c$ ). The resulting geoid is a combination of both internal (Figure $2 a)$ and boundary mass anomalies (Figure $2 b$ or $2 c$ ) and can be positive or negative, depending on the viscosity structure (compare Figure $2 a+2 b$ versus $2 a+2 c$ ).

The equations of motion of an incompressible selfgravitating spherical shell are presented in Richards and Hager [54] and Ricard et al. [50]. These equations can be solved by a separation of variables (assuming a radiallystratified viscosity). The resulting ODE's can be solved for response functions (kernels) which depend only on the viscosity structure. The geoid $(\delta \mathrm{Vlm})$ can then be calculated by convolving the response functions with a distribution of density contrasts as follows

$\delta V^{l m}=\frac{4 \pi \gamma a}{2 l+1} \int_{C}^{a} G^{1}(r, \eta(r)) \delta \rho^{l m}(r) d r$

where $\gamma$ is the gravitational constant, $a$ is the radius at the surface, $\mathrm{c}$ is the radius at the core, $\delta \rho^{l m}$ is the density contrast at a depth $r$ of spherical harmonic degree 1 and order $m$, and $G^{l}(r, \eta(r))$ is the geoid response kernel.

The density perturbations $\left(\delta \rho^{1 \mathrm{~m}}\right)$ are determined by seismic velocity perturbation models from seismic tomographic inversions and/or tectonic plate and slab models from boundary layer theory and deep earthquake locations in subduction zones. To transform seismic velocity anomalies into density anomalies, we assume that changes in seismic velocity can be mapped into changes in temperature and do not represent changes in composition. Seismic velocity variations can be written in terms of elastic moduli for which the limited experimental information places reasonable bounds. Thus, the density perturbations in equation 3 can be written as

$\delta \rho^{l m}=\frac{\delta \rho}{\delta v_{s}} \delta v_{s}^{l m}$

where $\delta \rho / \delta v_{s}$ is a velocity to density ratio and $\delta v_{s}{ }_{s}^{1 m}$ is the seismic velocity perturbation model.

A simple, two-layer viscosity modcl, with an increase in viscosity of a factor of ten at $670 \mathrm{~km}$ depth or $1200 \mathrm{~km}$ depth, explains the longest wavelength geoid from the inferred densities in the lower mantle $[11,18]$. This model is different from the two end-member, post-glacial rebound models. The differences between the models from post glacial rebound and the genid models have led to spirited debates, but until now no consensus model.

The velocities of the Earth's plates are the surface manifestations of convective flow in the mantle. Hager and O'Connell's model [15] showed that densities from the cooling of ocean plates and subducting slabs alone provide the necessary buoyancy force to drive plates at the observed velocities. Ricard et al. [50, 51], Ricard and Vigny [47], Forte and Peltier [10], and Forte et al. [12] used observed plate velocities to deduce the radial viscosity structure of the mantle. Plate velocities constrain the absolute value of the viscosity of the mantle; the geoid does not. The plate velocity data does not have the depth resolution of the geoid, because a low viscosity zone can effectively decouple the plates from flow in the deep interior.

In all of the studies discussed, the final viscosity model is dependent upon another model. In post-glacial rebound studies, this is a model of the ice sheet, which is only crudely known. In the case of the geoid, it is the seismic velocity models (see equations 3 and 4). Most seismic tomographic inversions do not report formal uncertainties (which are difficult to perform and, because of the difficulty in defining sources of error may have little 
TABLE 1. A Comparison of Recently Published Viscosity Structures

Determined by Systematic Forward Modeling (from [14])

\begin{tabular}{|c|c|c|c|c|}
\hline Model & $\underset{(\mathbf{k m})}{\mathbf{h}}$ & $\underset{(\mathrm{Pa} \mathrm{s})}{\eta_{11 \mathrm{~m}}}$ & $\underset{(\mathrm{Pa} \mathrm{s})}{\eta_{1 \mathrm{~m}}}$ & $\eta_{1 m} / \eta_{11 m}$ \\
\hline $\mathrm{PT}^{\mathrm{a}}$ & 120 & $10^{21}$ & $2 \times 10^{21}$ & 2 \\
\hline $\mathbf{M P}^{\mathbf{b}}$ & 120 & $10^{21}$ & $4.5 \times 10^{21}$ & 4 \\
\hline LJN2 $2^{c}$ & 100 & $3.5 \times 10^{20}$ & $4.7 \times 10^{21}$ & 15 \\
\hline $\mathrm{LJN}^{\mathrm{d}}$ & 150 & $3.8 \times 10^{20}$ & $3.4 \times 10^{21}$ & 8 \\
\hline LNA $^{\mathrm{e}}$ & 75 & $2 \times 10^{20}$ & $7.5 \times 10^{21}$ & 40 \\
\hline NLO $^{\mathbf{f}}$ & 50 & $10^{20}$ & $10^{22}$ & 100 \\
\hline RVGPg & $(100)$ & $2.6 \times 10^{20}$ & $1.3 \times 10^{22}$ & 50 \\
\hline HGPA $^{h}$ & $(100)$ & $2 \times 10^{19}$ & $6 \times 10^{21}$ & 300 \\
\hline$H^{i}$ & $(100)$ & $2 \times 10^{20}$ & $6 \times 10^{21}$ & 30 \\
\hline
\end{tabular}

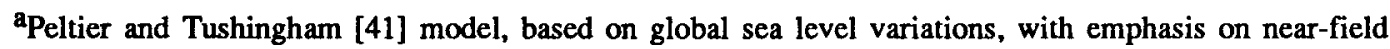
sites.

b Mitrovica and Peltier [29] model, based on the assumption that the gravity anomaly over Hudson Bay is totally due to delayed rebound.

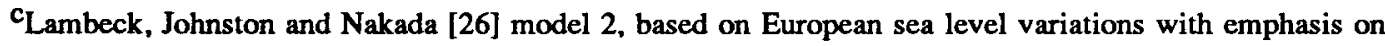
relative variations in sites away from the ice margins.

${ }^{\mathrm{d}}$ Lambeck, Johnston and Nakada [26] model 3, an alternative to model 2.

${ }^{e}$ Lambeck and Nakada [25] model for Australia, based on sea level variations with emphasis on relative variations in sites spanning the continental margin.

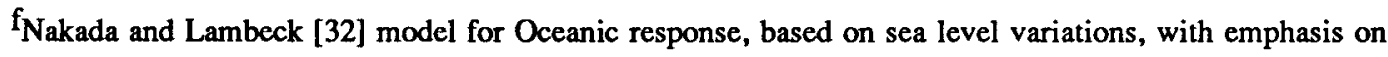
relative variations as a function of island size.

gRicard and Vigny [47] model from the Geoid and Plate velocities. Parentheses on (h) indicate the thickness of the high viscosity lid.

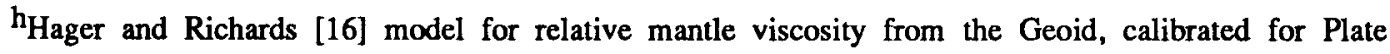
velocities and Advected heat flux [14]. An additional layer, from $400 \mathrm{~km}$ to $670 \mathrm{~km}$ depth has a viscosity of $6 \times 10^{20} \mathrm{~Pa} \mathrm{~s}$.

${ }^{i_{A}}$ modification of model HRGP that has an asthenospheric viscosity higher by a factor of 10 , as might be expected for Shield regions. 


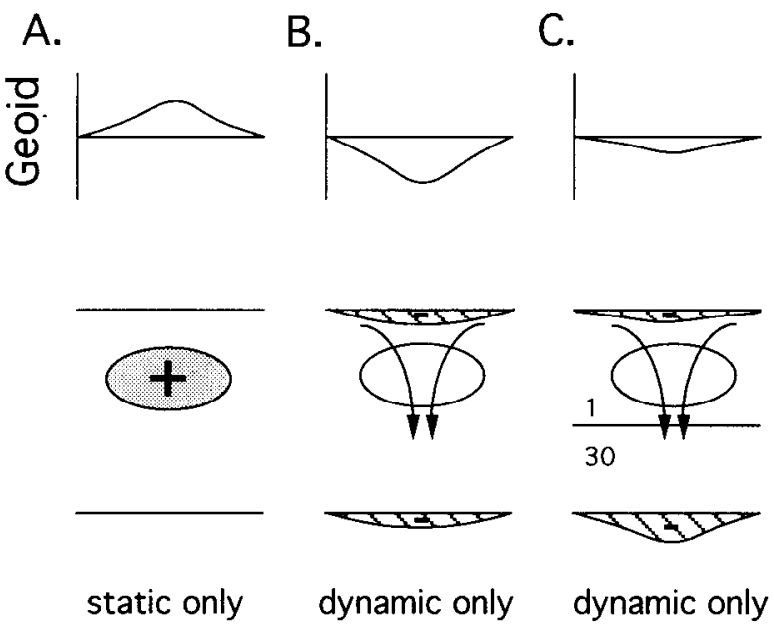

Fig. 2. (a) The geoid anomaly over a positive mass anomaly (stippled) in a static earth. (b) The dynamic flow driven by the mass anomaly causes negative mass anomalies (stripped regions) at the upper and lower boundaries, hence negative geoid anomalies. The sum of (a) and (b) is a negative anomaly in a uniform viscosity medium. (c) With an increased viscosity in the lower layer, the dynamic topography of the surface is reduced and the sum of (a) plus (c) could be positive.

meaning). The use of different seismic models can produce different viscosity models [23, 51], suggesting that crude viscosity models may already be pushing the limit of the observations. Plate velocity models also have associated uncertainties; in addition, only the poloidal part of the plate velocities are driven by viscous flow without lateral variations in viscosity. Because they are ignored in the viscous flow formulations, lateral variations in viscosity themselves could also introduce a major source of error in the viscosity models.

Studies of Earth's rotation provide constraints on mantle viscosity. O'Connell [33] suggests that changing patterns of convection would change the principlc moments of inertia of the Earth and that his viscosity model would permit polar wander from convection. Sabadini and Peltier [57] and Wu and Peltier [67] discuss the changes in Earth's rotation due to Pleistocene deglaciation. Ricard and Sabadini [48] discuss changes in rotation induced by density anomalies in the mantle. Polar wander also has recently been demonstrated to provide constraints on mantle viscosity [e.g., 53, 58]. A number of recent papers summarizing these results (and the post glacial uplift, geoid and plate velocity studies) can be found in Glacial Isostasy, Sea-Level and Mantle Rheology, ed. Sabadini, Lambeck and Boschi [59].

\section{RECENT INVERSION RESULTS}

Several recent studies form and solve inverse problems rather than repeatedly solving the forward problem. In theory, the inverse problem provides not only a model, but also estimates of the resolving power of the data and of the trade-offs between model parameters. The resolution and trade-off analyses are not always straight-forward. There is a surprising convergence of these results and the resulting model differs from the "traditional" models. In this paper, all of the figures will present relative viscosities. To convert to absolute viscosities (in $\mathrm{Pa} \mathrm{s}$ ), one should multiply the horizontal axis scale by $10^{21} \mathrm{~Pa}$ s. Geoid models are only sensitive to relative viscosities, so the absolute scale is chosen to be consistent with postglacial rebound and plate velocity studies.

\subsection{Plate Velocity Inversion}

Forte et al. [12] used the method of Bayesian inference to invert for the radial viscosity profile which best fit the observed plate velocities. Harmonic coefficients of the observed plate divergence in the degree range $1=1-8$ were used [10]. Using a tomographic shear wave model SH425.2 - [62] as the driving force (i.e., $\delta v_{s} \operatorname{lm}$ in equation 4) and Greens functions (kernels) for viscous flow developed in Forte and Peltier [10], they parameterized the mantle viscosity in five layers $(0-100 \mathrm{~km}, 100-400 \mathrm{~km}$, $400-670 \mathrm{~km}, 670-2600 \mathrm{~km}$ and $2600 \mathrm{~km}$ to the CMB). Their inversion produced a viscosity model (i.e., the best fitting uniform viscosity in each of the five layers) with a low viscosity in the transition zone and high viscosity in the $100-400 \mathrm{~km}$ layer with a factor of 42 jump at $670 \mathrm{~km}$ (see Figure 3). The plate-like divergence predicted by this model explains $48 \%$ of the variance in the observed plate divergence (in the range $1=1-15$ ). Prior to the inversion, the variance reduction with an isoviscous mantle was $770 \%$. However, there is a significant trade-off between the top three layers $(0-100 \mathrm{~km}$ and $400-670 \mathrm{~km}$ are correlated and $100-400 \mathrm{~km}$ is anti-correlated with the others), so a model with a low viscosity in the $100-400 \mathrm{~km}$ layer and higher viscosities in the 0-100 km layer and 400$670 \mathrm{~km}$ layers fits the data nearly as well (see also Figure 3).

Ricard and Wuming [49], using the lower mantle model of Dziewonski [8] and the upper mantle model of Woodhouse and Dziewonski [66], invert the topography, geoid, rotation poles, and angular plate velocities for mantle viscosity. Using present day plate geometries, the surface velocity boundary condition is choosen to match the stresses between a no-slip boundary condition at the surface flow driven by the internal density contrasts and 


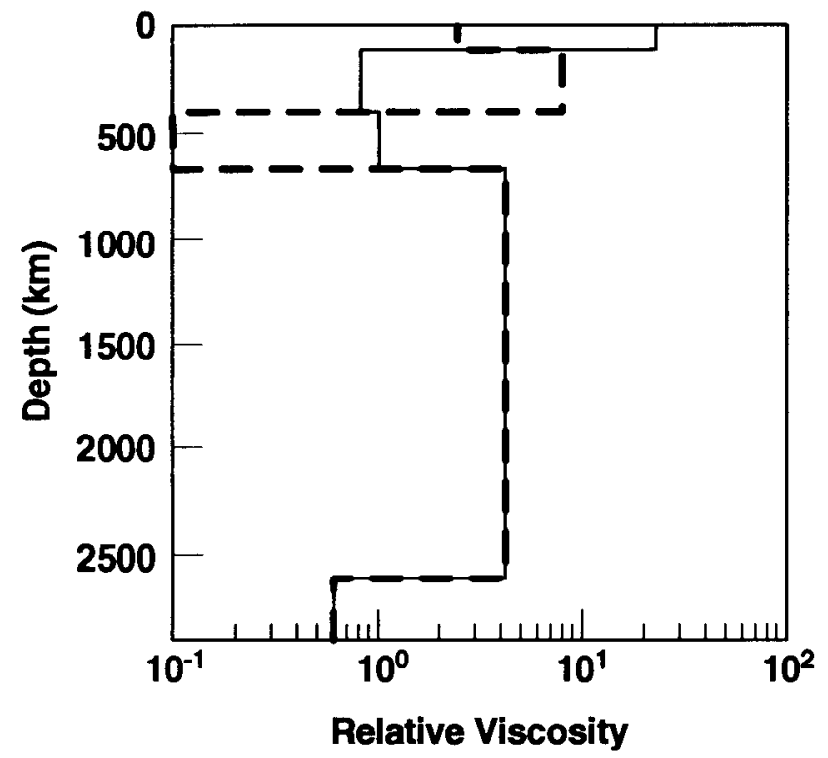

Fig. 3. 1-D viscosity models from Forte et al. [12] determined by inverting observed plate velocities for the best fitting 5 layer viscosity model. The dashed line is the preferred model, the solid line is also an acceptable model. The viscosities in this plot are scaled by a characteristic mantle viscosity $\left(\eta=10^{21} \mathrm{~Pa} \mathrm{~s}\right)$.

flow driven by the plates. The resulting viscosity model has a continuous increase in viscosity with depth to the mid-lower mantle, then a decrease in viscosity in the lower one-third of the lower mantle, with no noticeable discontinuities or low viscosity zones. There is a peak change in viscosity of about two orders of magnitude from the surface to the maximum in the lower mantle. However, this model provides poor fits to the data; variance reductions are $44 \%$ for geoid, $58 \%$ for topography, and $19 \%$ for poliodal component of the plate velocities.

\subsection{Post Glacial Uplift Inversions}

There have been several attempts to form and solve an inverse problem for the viscosity of the mantle using postglacial uplift data $[35,38]$. An analysis of the relative sea level, or uplift history, over Hudson Bay was performed by Mitrovica and Peltier [30, 31]. The horizontal extent of the Laurentide ice sheet suggests that this subset of the relative sea level (RSL) data should be sensitive to the viscosity at greater depths than other data subsets [30]. They conclude that the preference of a uniform viscosity in the lowcr mantle of $10^{21} \mathrm{~Pa}$ s from other studies [e.g., $2,4,5,42]$ is more appropriately interpreted as a constraint on the uppermost part of the lower mantle (i.e.,
$670-1800 \mathrm{~km}$ ), with very weak sensitivity to changes in viscosity of up to an order of magnitude below this depth or in the upper mantle. Therefore, models with large increases in viscosity with depth cannot be ruled out by the RSL data as long as the average viscosity in the 670-1800 $\mathrm{km}$ depth range is $10^{21} \mathrm{~Pa}$ s. It should be pointed out that Haskell [20] indicated that his result represented the avcrage viscosity of the mantle.

\subsection{Geoid Inversion}

Ricard et al. [51] considered a three layer mantle. They used L02.56 [8] for the densities in the lower mantle, and M84C [66] and a slab model for those in the upper mantle; they also solved for the density to velocity ratio $(\delta \rho / \delta v$ - see equation 4$)$ in the upper and lower mantle, the density coefficient for the slab model ( $\left.\rho_{\text {slab }}\right)$, and viscosities in 100-300,300-670, and 670-2900 km layers, giving them six unknowns. They used the response kernels for Newtonian viscous flow [50], and chose the viscosity value in the $0-100 \mathrm{~km}$ layer to be $10^{22} \mathrm{~Pa} \mathrm{~s}$, because the geoid is sensitive only to relative viscosity change. They performed a Monte Carlo inversion for the viscosity model which best fit both the geoid and plate velocities. Two classes of models emerged from their study; one with an increasing viscosity with depth (Figure 4 - solid line) and another with the highest viscosity in the transition region and lower viscosity in the upper 100-300

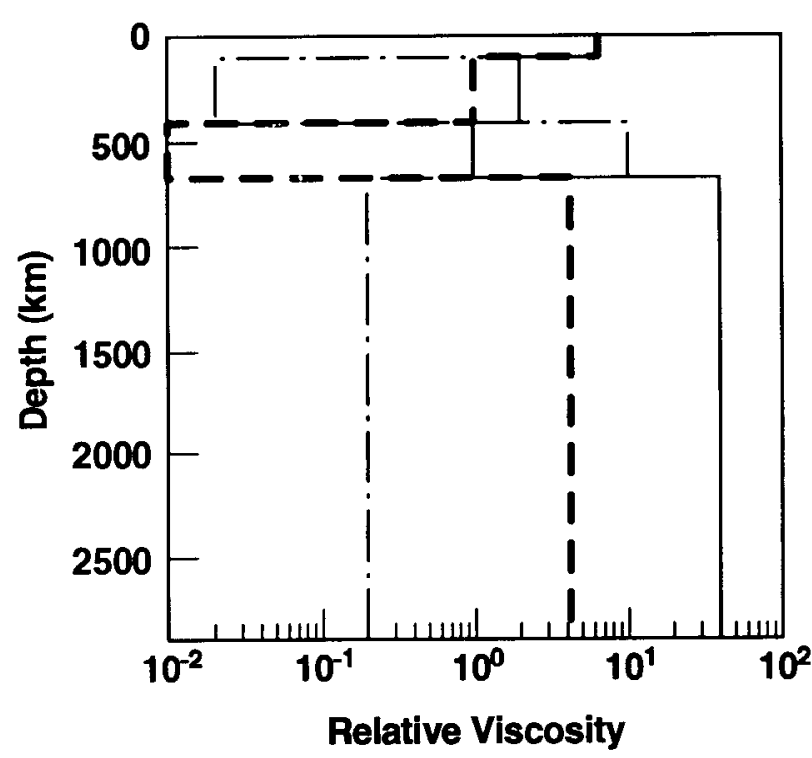

Fig. 4. Three representative 1-D viscosity models from Ricard et al. [51] from Monte Carlo inversion using geoid and plate velocities. The viscosities in this plot are scaled by a charactcristic mantle viscosity $\left(\eta=10^{21} \mathrm{~Pa} \mathrm{~s}\right)$. 
$\mathrm{km}$ and 670-2900 km regions (Figure 4 - dash dot line). However, including the plate velocities, in addition to the geoid, a third model emerged (Figure 4 - heavy dashed line). One of their strongest conclusions is the sensitivity of their modeling to the assumed density model. As they note, Hager et al. [18] obtained better results with the same formalism using Clayton and Comers' [6] lower mantle and a boundary layer theory slab upper mantle. The more interesting result is the model that emerged when they considered both geoid and plate velocities in the inversion (Figure 4 - heavy dashed line). In addition, Ricard et al. [51] are the only investigators of the recent group to consider chemically stratified mantle models. Their results suggest that, based on the inversion study, the data are unable to discriminate between layered or whole mantle models.

A study by King and Masters [23] considered several published models for $\mathbf{S}$-wave velocity for the densities providing the driving force ( $\delta \rho$ in equation 3): MDLSH [63]; SH425.2 [62]; and MODSH.C [27]. Using the selfgravitating Green's functions for Newtonian viscous flow, following Richards and Hager [54] and Ricard et al. [50], they inverted for radial viscosity models that best fit the observed $1=2-8$ geoid $(1=2-6$ for MDLSH) using a nonnegative, least-squares scheme with smoothing to inhibit

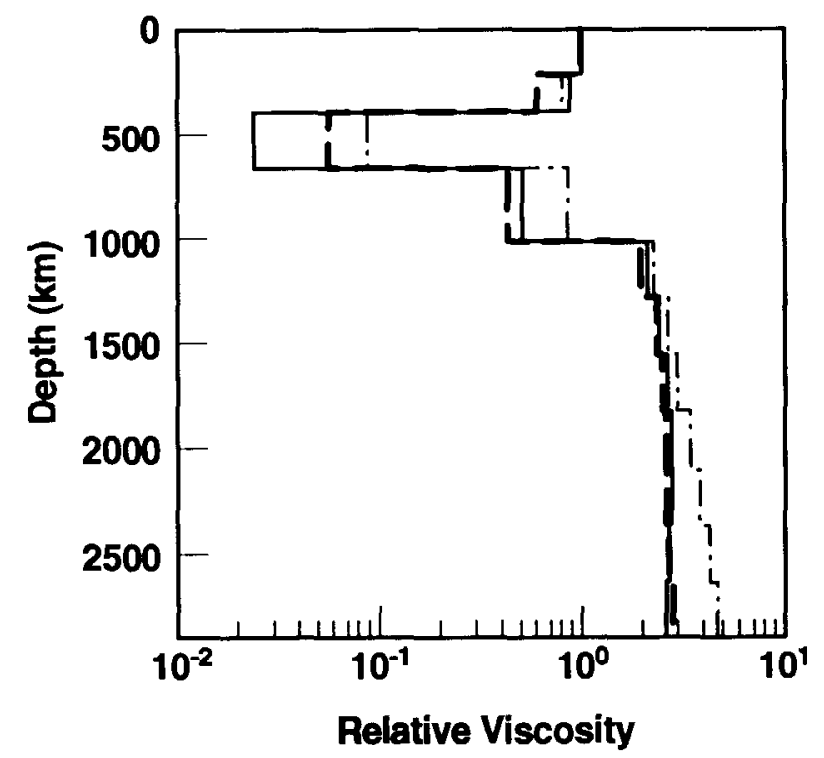

Fig. 5. 1-D viscosity models from King and Masters [23] determined by inverting the seismically determined density anomalies for the best fitting 11 layer viscosity model using the gcoid. The models are normalized by the viscosity in the 1284 to 1555 region. The viscosities in this plot are scaled by a characteristic mantle viscosity ( $\eta$ $=10^{21} \mathrm{~Pa} \mathrm{~s}$ ).

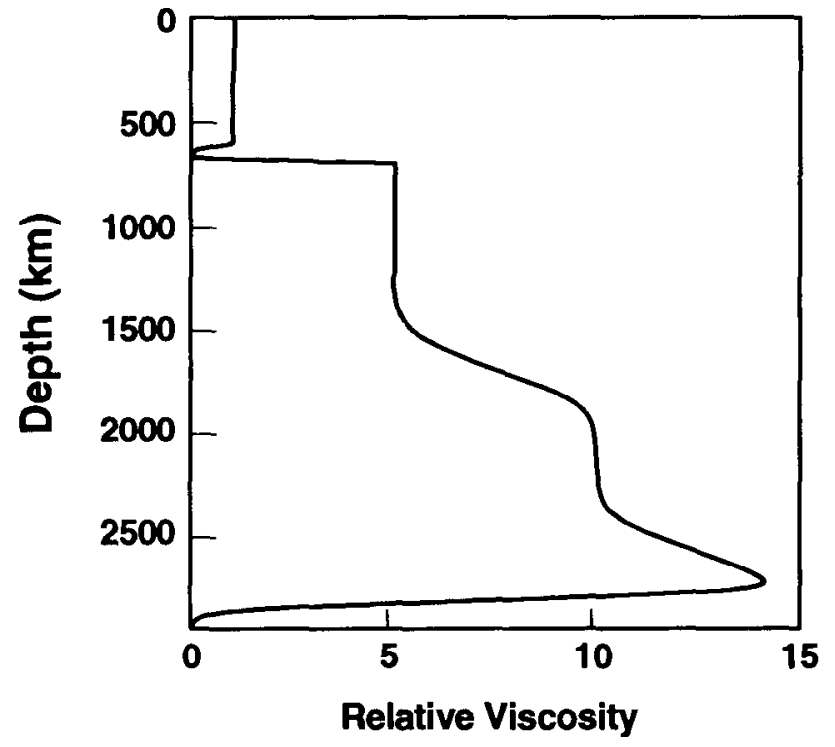

Fig. 6. 1-D viscosity model from Forte et al. [13]. This forward model provides good fits to geoid and plate velocities. It compares well with Figures 3,4 and 5. The viscosities in this plot are scaled by a characteristic mantle viscosity ( $\eta=10^{21} \mathrm{~Pa} \mathrm{~s}$ ).

wild oscillations. All three of the seismic velocity models predict a low viscosity between $400-670 \mathrm{~km}$ depth (Figure 5). The pattern of viscosity with depth for the three models is strikingly similar: a high viscosity from 0 to 400 $\mathrm{km}$ depth, a low viscosity between 400 and $670 \mathrm{~km}$, and increasing viscosity below $670 \mathrm{~km}$. The largest difference between the viscosity models is a factor of two difference in the viscosity of the $400-670 \mathrm{~km}$ layer. It is interesting to note that the viscosity in the lower mantle increases by a factor of five below $1022 \mathrm{~km}$ in addition to an increase at $670 \mathrm{~km}$. This resembles the two-layer model of Forte and Peltier [11].

Forte et al. [13] used the recent S-wave model SH8/U4L8 which they describe. Using Frechet kemels [Forte et al., 12], they determine the viscosity profile required to fit the geoid. The model, which contains a thin, low-viscosity zone at the base of the upper mantle and an increase in viscosity in the lower mantle (Figure 6), is quite similar to those determined by King and Masters [23] (Figure 5). It may be beyond the limit of their data to constrain such a thin layer at the base of the mantle, however; because layer thickness and viscosity contrast trade-off directly, this could possibly represent a thicker, less extreme layer. Forte et al. obtain a $65 \%$ variance reduction for the observed geoid $(1=2-8)$, in addition to a reasonable fit to the plate velocities with these viscosity and density models. They also point out that their 
viscosity model is consistent with recent post-glacial uplift analyses and mineral physics.

\section{COMPARISON}

The viscosity model from Forte et al. [12] - determined by inversion using the plate velocity data, the viscosity models from King and Masters [23] - determined by inversion using the geoid data, and the viscosity model from Ricard et al. [51] - using a Monte Carlo inversion of geoid and plate velocity data - are remarkably similar. Furthermore, the results of the post-glacial uplift inversion by Mitrovica and Peltier [30] and the experimental data, as discussed by Ranalli [46], seem compatible with these observations. Upon considering both the uncertainty in the internal densities and surface loads and the uncertainties in the viscosity models themselves, it appears that the results from the different observations are compatible. However, if the transition zone is $\mathrm{Ca}$ rich, as suggested by some [1], Karato's [21] results on the strength of gamet are incompatible with this new model. Mantle models with a hard transition zone appear compatible with observations [60].

\section{LATERAL VISCOSITY VARIATIONS}

An area of increasing interest is the role of lateral variations in viscosity and their effect on post-glacial rebound, plate velocity and geoid predictions. Using perturbation theory on a 2-D Cartesian problem, Richards and Hager [55] suggested this effect would be small for long-wavelength structures in the lower mantle. Ritzler and Jacobi [56], however, suggest that, because radial viscosity models underpredict the geoid compared to their lateral viscosity equivalants, neglecting lateral viscosity variations leads to errors in the magnitude of radial viscosity jumps as much as a factor of two. Zhang and Christensen [68] also find that the effects of lateral viscosity variations are significant, especially when the radial viscosity is stratified. Ricard et al. [52] showed that a model with lateral viscosity variations between continental and oceanic asthenosphere is consistent with the observed global rotation of the lithosphere with respect to the hot spot reference frame (i.e., the degree 1 toroidal component of plate velocities). A number of investigations addressing lateral viscosity variations are currently underway.

Acknowledgments. The author acknowledges support from NSF grant EAR-9117406. Thanks to R. O'Connell, A. Forte, and Y. Ricard for providing theses, reprints, and preprints. Thanks also to the numerous anonymous reviewers whose comments helped improve this manuscript. Special thanks to Kathy Kincade for help in preparing this manuscript.

\section{REFERENCES}

1. Anderson, D.L., Theory of the Earth, pp. 57-62, Blackwell Scientific Publications, Boston, 1989.

2. Andrews, J.T., A Geomorphological Study of Postglacial Uplift with Particular Reference to Arctic Canada, 156 pp., Inst. British Geographers, London, 1970.

3. Ashby, M.F., and R.A. Verrall, Micromechanisms of flow and fracture, and their relevance to the rheology of the upper mantle, Phil. Trans. R. Soc. Lond. A, 288, 59-95, 1978.

4. Cathles, L.M., The viscosity of the Earth's mantle. Ph.D. thesis, Princeton University, 1971.

5. Cathles, L.M., The Viscosity of the Earth's Mantle, 386 pp., Princeton
University Press, Princeton, NJ, 1975.

6. Clayton, R.W., and R.P. Comer, A tomographic analysis of mantle heterogeneities from body wave travel time (abstract), EOS, Trans. $A G U, 62,776,1983$.

7. Daly, R.A., The Changing World of the Ice Age, 271 pp., Yale University Press, New Haven, CT, 1934.

8. Dziewonski, A.M., Mapping the lower mantle: determination of lateral heterogeneity in $P$ velocity up to degree and order 6., J. Geophys. Res., 89, 5929-5952, 1984.

9. Dziewonski, A.M., B.H. Hager, and R.J. O'Connell, Large-scale heterogeneities in the lower mantle, J. Geophys. Res., 82, 239-255, 1977.
10. Forte, A.M., and W.R. Peltier, Plate tectonics and aspherical Earth structure: the importance of polidaltoroidal coupling, J. Geophys. Res., 92, 3645-3679, 1987.

11. Forte, A.M., and R. Peltier, Viscous flow models of global geophysical observables 1. forward problems, $J$. Geophys. Res., 96, 29,131-20,159, 1991.

12. Forte, A.M., W.R. Peltier, and A.M. Dziewonski, Inferences of mantle viscosity from tectonic plate velocities, Geophys. Res. Lett., I8, 1747-1750, 1991.

13. Forte, A.M., A.M. Dziewonski, and R.L. Woodward, Aspherical structure of the mantle, tectonic plate motions, nonhydrostatic geoid, and topography 
of the core-mantle boundary, in Proceedings of the IUGG Symposium 6: Dynamics of the Earth's Deep Interior and Rotation, edited by J.L. Le Mouel, in press, 1993.

14. Hager, B.H., Mantle viscosity: A comparison of models from postglacial rebound and from the geoid, plate driving forces, and advected heat flux, in Glacial Isostasy, Sea-Level and Mantle Rheology, edited by R. Sabadini, K. Lambeck, and E. Boschi, pp. 493 513, Kluwer Academic Publishers, London, 1991.

15. Hager, B.H., and R.J. O'Connell, A simple global model of plate dynamics and mantle convection, $J$. Geophys. Res., 86, 4843-4867, 1981.

16. Hager, B.H., and M.A. Richards, Long-wavelength variations in Earth's geoid: physical models and dynamical implications, Phil. Trans. R. Soc. Lond. A, 328, 309-327, 1989.

17. Hager, B.H., and R.W. Clayton, Constraints on the structure of mantle convection using seismic observations, flow models, and the geoid, in Mantle Convection, edited by W.R. Peltier, pp. 657-763, Gordon and Breach, New York, 1989.

18. Hager, B.H., R.W. Clayton, M.A. Richards, R.P. Comer, and A.M. Dziewonski, Lower mantle heterogeneity, dynamic topogrpahy and the geoid, Nature, 313, 541-545, 1985.

19. Haskell, N.A., The motion of a viscous fluid under a surface load, I, Physics, 6, 265-269, 1935.

20. Haskell, N.A., The motion of a viscous fluid under a surface load, II, Physics, 7, 56-61, 1936.

21. Karato, S-I., Plasticity-crystal structure systematics in dense oxides and its implications for the creep strength of the Earth's deep interior: A preliminary result, Phys. Earth Planet. Int., 55, 234-240, 1989.

22. Karato, S-I., and P. Li, Diffusive creep in perovskites: Implications for the rheology of the lower mantle,
Science, 255, 1238-1240, 1992.

23. King, S.D., and G. Masters, An inversion for radial viscosity structure using seismic tomography, Geophys. Res. Lett., 19, 1551-1554, 1992.

24. Kirby, S. H., Rheology of the lithosphere, Rev. Geophys. Space Phys., 21, 1458-1487, 1983.

25. Lambeck, K. and M. Nakada, Late Pleistocene and Holocene sea-level change along the Australian coast, Global Planet. Change, 1990.

26. Lambeck, K., P. Johnston, and M. Nakada, Glacial rebound and sealevel change in northwestern Europe, Geophys. J. Int., 1990.

27. Masters, G., and H. Bolton, Longperiod $S$ travel times and the threedimensional structure of the mantle, J. Geophys. Res., in press. 1993.

28. McConnell, R.K., Viscosity of the mantle from relaxation time spectra of isostatic adjustment, J. Geophys. Res., 73, 7089-7105, 1968.

29. Mitrovica, J.X., and W.R. Peltier, Radial resolution in the inference of mantle viscosity from observations of glacial isosatic adjustment, in Glacial Isostasy, Sea-Level and Mantle Rheology, edited by R. Sabadini, K. Lambeck, and E. Boschi, pp. 63-78, Kluwer Academic Publishers, London, 1991.

30. Mitrovica, J.X. and W.R. Peltier, A complete formalism for the inversion of post-glacial rebound data Resolving power analysis, Geophys. J. Int., 104, 267-288, 1991.

31. Mitrovica, J.X., and W.R. Peltier, A comparison of methods for the inversion of viscoclastic relaxation spectra, Geophys. J. Int., 108, 410414, 1992.

32. Nakada, M., and K. Lambeck, Late Pleistocene and Holocene sea-level change in the Australian region and mantle rheology, J. Geophys. Res., 96, 497-517, 1989.

33. O'Connell, R.J., Pleistocene glaciation and the viscosity of the lower mantle, Geophys. J.R. astr.
Soc., 23, 299-327, 1971.

34. O'Connell, R.J., The effects of mantle phase changes on postglacial rebound, J. Geophys. Res., 81, 971974, 1976.

35. Parsuns, B.E., Changes in the Earth's shape, Ph.D. thesis, Cambridge Univcrsity, Cambridge, 1972.

36. Pekris, C.L., Thermal convection in the interior of the Earth, Mon. Not. R. Astron. Soc., Geophys. Suppl., 3, 343-367, 1935.

37. Peltier, W.R., The impulse response of a Maxwell, Rev. Geophys. Space Phys., 12, 649-669, 1974.

38. Peltier, W.R., Glacial isostatic adjustment. II, The inverse problem. Geophys. JR. astr. Soc., 46, 669-706, 1976.

39. Peltier, W.R., Mantle viscosity, in Mantle Convection, edited by W.R. Peltier, pp. 389-478, Gordon and Breach, New York, 1989.

40. Peltier, W.R., and J.T. Andrews, Glacial isostatic adjustment, I, The forward problem, Geophys. Astr. Soc., 46, 605-646, 1976.

41. Peltier, W.R., and A.M. Tushingham, Global sea level rise and the greenhouse effect: Might they be connected?, Science, 244, 806-810, 1989.

42. Peltier, W.R., W.E. Farrell, and J.A. Clark, Glacial isostasy and relative sea level: A global finite element model. Tectonophysics, 50, 81-110, 1978.

43. Poirier, J-P., Creep of Crystals, 264 pp., Cambridge University Press, Cambridge, 1985.

44. Poirier, J-P., Plastic rheology of crystals, in $A G U$ Handbook of Physical Constants, this volume, 1993.

45. Ranalli, G., Rheology of the Earth: Deformation and Flow Processes in Geophysics and Geodynamics, 366 pp., Allen and Unwin, Boston, 1987.

46. Ranalli, G., The microphysical approach to mantle rheology, in, Glacial Isostacy, Sea-Level, and 
Mantle Rheology, edited by $\mathbf{R}$. Sabadini, K. Lambeck, and E. Boschi, pp., 343-378, Kluwer Academic Publishers, London, 1991.

47. Ricard, Y., and C. Vigny, Mantle dynamics with induced plate tectonics, J. Geophys. Res., 94. 17,543-17,559, 1989.

48. Ricard, Y., and R. Sabadini, Rotational instabilities of the earth induced by mantle density anomalies, Geophys. Res. Lett., 17, 1990.

49. Ricard, Y., and B. Wuming, Inferring the viscosity and 3-D density structure of the mantle from geoid, topography, and plate velocities, Geophys. J. Int., 105, 561-571, 1991.

50. Ricard, Y., L. Fleiotout, and C. Froidevaux, Geoid heights and lithospheric stresses for a dynamic Earth, Ann. Geophys., 2, 267-286, 1984.

51. Ricard, Y., C. Vigny, and C. Froidevaux, Mantle heterogeneities, geoid and plate motion: A Monte Carlo inversion, J. Geophys. Res., 94, 13.739-13.,754, 1989.

52. Ricard, Y., C. Doglioni, and R. Sabadini, Differential rotation between lithosphere and mantle: A consequence of lateral mantle viscosity variations, J. Geophys. Res., 96, 8407-8415, 1991.

53. Ricard, Y., G. Spada, and R. Sabadini, Polar wandering of a dynamic earth, Geophys. J. Int., in press, 1993.

54. Richards, M.A., and B.H. Hager, Genid anomalies in a dynamic earth, J. Geophys. Res., 89, 5987-6002, 1984.

55. Richards, M.A., and B.H. Hager, Effects of lateral viscosity variations on long-wavelength geoid anomalies and topography, J. Geophys. Res., 94, 10,299-10,313, 1989.

56. Ritzler, M., and W.R. Jacobi, Geoid effects in a convecting system with lateral viscosity variations, Geophys. Res. Lett., 19, 1547-1550, 1992.

57. Sabadini, R., and W.R. Peltier, Pleistocene deglaciation and the Earth's rotation: Implications for mantle viscosity, Geophys. J.R. astr. Soc., 66, 553-578, 1981.

58. Sabadini, R., and D.A. Yuen, Mantle stratification and long-term polar wander, Nature, 339, 373-375, 1989.

59. Sabadini, R., K. Lambeck, and E. Boschi (Eds.), Glacial Isostacy, SeaLevel, and Mantle Rheology, 708 pp., Kluwer Academic Publishers, London, 1991.

60. Spada, G., R. Sabadini, D.A. Yuen, and Y. Ricard, Effects on post-glacial rebound from the hard rheology in the transition zone, Geophys. J., 109, 1992.

61. Stocker, R.L., and M.F. Ashby, On the rheology of the upper mantle, Rev. Geophys. Space Phys., 11, 391426, 1973.
62. Su, W-J., and A.M. Dziewonski, Predominance of long-wavelength heterngeneity in the mantle, Nature, $352,121-126,1991$.

63. Tanimoto, T., Long-wavelength Swave velocity structure throughout the mantle, Geophys. J. Int., 100, 327-336, 1990.

64. van Bemmelen, R.W., and H.P. Berlage, Versuch Einer Mathematischen Behandlung Geoteknisher Bewegungen Unter Besonderer Berucksichtegung der Undationstheorie, Gerlands Beitrage zur Geophsysik, 43, 19-55, 1935.

65. Weertman, J., The creep strength of the Earth's mantle, Rev. Geophys. Space Phys., 8, 145-168, 1970.

66. Woodhouse, J.H., and A.M. Dziewonski, Mapping the upper mantle: Three-dimensional modeling of earth structure by inversion of seismic waveforms, J. Geophys. Res., 89, 5953-5986, 1984.

67. Wu, P., and W.R. Peltier, Pleistocene glaciation and the Earth's rotation: $A$ new analysis, Geophys. J. R. astr. Soc., 76, 753-791, 1984.

68. Zhang, S., and U. Christensen, The effect of lateral viscosity variations on geoid topography and plate motions induced by density anomalies in the mantle, Geophys. $J$. Int., submitted, 1992. 